\title{
Research on Construction of Innovation Cloud Service Platform in Power Enterprise
}

\author{
Li Wei $^{1}$, Zhao Yongbin ${ }^{1}$, Han Jieping ${ }^{2}$, Zhang Zhiru ${ }^{1}$, Yu Hai ${ }^{1}$ \\ ${ }^{1}$ State Grid Liaoning Electric Power Supply Co., LTD. Information \&Telecommunication Branch, Shenyang, Liaoning 110006, China \\ ${ }^{2}$ Northeast Electric Power University, Changchun, Jilin, 132012, China
}

\begin{abstract}
The informalization and automation of the present power system have important influences on the smooth operation of power stations and systems. The construction of the innovation cloud service platform could help manage the power enterprise. Three components including data center, monitoring system, and decision support system are established to realize the functions of data sharing, intelligent management, and remote support. Through the establishment of the innovation cloud service platform, the whole efficiency and effectiveness of the power enterprise can be enhanced, which helps the smooth operation of the power stations and systems.
\end{abstract}

\section{Introduction}

With the fast development of information technology, the intelligent enterprise is a necessary trend at present and in the future [1-4]. The electrical power system has important influences on people's daily life. In order to maintain the smooth operation of the whole power system, the innovation cloud service platform should be constructed and applied to production, operating, and management. In the previous works, many artificial intelligence algorithms have been applied to the management of power system including data backup, information monitoring, fault diagnosis, anomaly detection, etc. [5-16]. In order to further enhance the automation level of the power system, the innovation cloud service platform should be developed using innovation technologies in the field of artificial intelligence. Based on the innovation cloud service platform, the data from different power stations could be stored together and shared. In this way, more historical data can be used to train more robust model for the management of power system. The stored data can be monitored automatically by classification and information detection. When there is anomaly in the data flows, the innovation cloud service platform could report the problems to the workers. In the meantime, the innovation cloud service platform could provide some feasible suggestions to handle the problems. By the innovation cloud service platform, workers from different stations could help each other via remote control. So, all the stations could be unified together to maintain the smooth operating of the power system [1721].

In this paper, we study on the construction of innovation cloud service platform in power enterprise. Considering the defaults in the present power system, the objective of construction the innovation cloud service platform is first analyzed as the start point. Then, the necessary combinations of the innovation cloud service platform are discussed including data center, monitoring system, and decision support system. The three combinations have different functions and they complement each other to manage the smooth operating of the whole power system. The data center stores the data flows from all the power stations. Then, the monitoring system analyses the data flows to find the anomaly and detect the faults so the potential problems can be found immediately. Finally, the decision support system provides feasible ways to handle the potential problems. Therefore, based on the innovation cloud service platform, the robustness and efficiency of the whole power system can be enhanced.

\section{Objective of Innovation Cloud Service Platform}

The innovation cloud service platform is constructed to enhance the whole efficiency and effectiveness of the whole power system. The main objectives of the innovation cloud service platform can be summarized as data sharing, intelligent management, and remote support.

\subsection{Data sharing}

With the fast increase of power stations and power systems, there is a large amount of data in the power system. Therefore, the data from different stations and systems should be shared so the available historical data can be greatly enriched. The innovation cloud service platform is constructed to manage the data and classify them. And different power stations and systems can 
share and use the data. Therefore, data sharing is the basic function of the built innovation cloud service platform.

\subsection{Intelligent management}

As there a large amount of data in the power system, it should be managed intelligently to improve the efficiency. First, the data flows should be classified to several categories, e.g., hardware information, software information, network information, etc. In each category, the data flow is checked and detected so the anomaly can be found and located at first time. The system further analyses the detected problems and diagnose its properties.

\subsection{Remote support}

The power stations may distribute at different locations and it is difficult to make them operate as a whole. The innovation cloud service platform is constructed to unify all the power stations and systems so they can operate cooperatively. At different power stations, they process the data individually. Once there is an anomaly, the station could report it to other stations. Also, different stations could help each other to handle the problem. Therefore, the found problem can be solved with high efficiency.

\section{Construction of Innovation Cloud Service Platform}

\subsection{Data center}

To realize the objectives of the innovation cloud service platform, some functional parts should be built and operated. The data center is an essential component of the innovation cloud service platform, which stores the data from different power stations and systems. Also, all the data is classified as several categories for improve the management efficiency. The effective data should be separately stored as useful historical data for the future use.

\subsection{Monitoring system}

The monitoring system is also essential in the innovation cloud service platform, which analyses the data flows from the data center. The artificial intelligence techniques are used to analyses the data and detect the anomaly. Furthermore, the detected problems are recognized based on the model trained by the historical data. Through the monitoring system, the potential problems occurred in the power stations and systems could be detected at the first time. Meanwhile, the found problems are also used to update the data center to improve its historical data.

\subsection{Decision support system}

The decision support system is incorporated in the innovation cloud service platform to help handle the occurred problems in the data flows from the power stations and systems. The decision support system is developed based on the artificial intelligence, which could perform training based on the large amount of historical data. Based on the trained model, the detected problems from the monitoring system can be quickly classified. Then, according to the label of the problem, the corresponding solutions can be provided by the system to the workers.

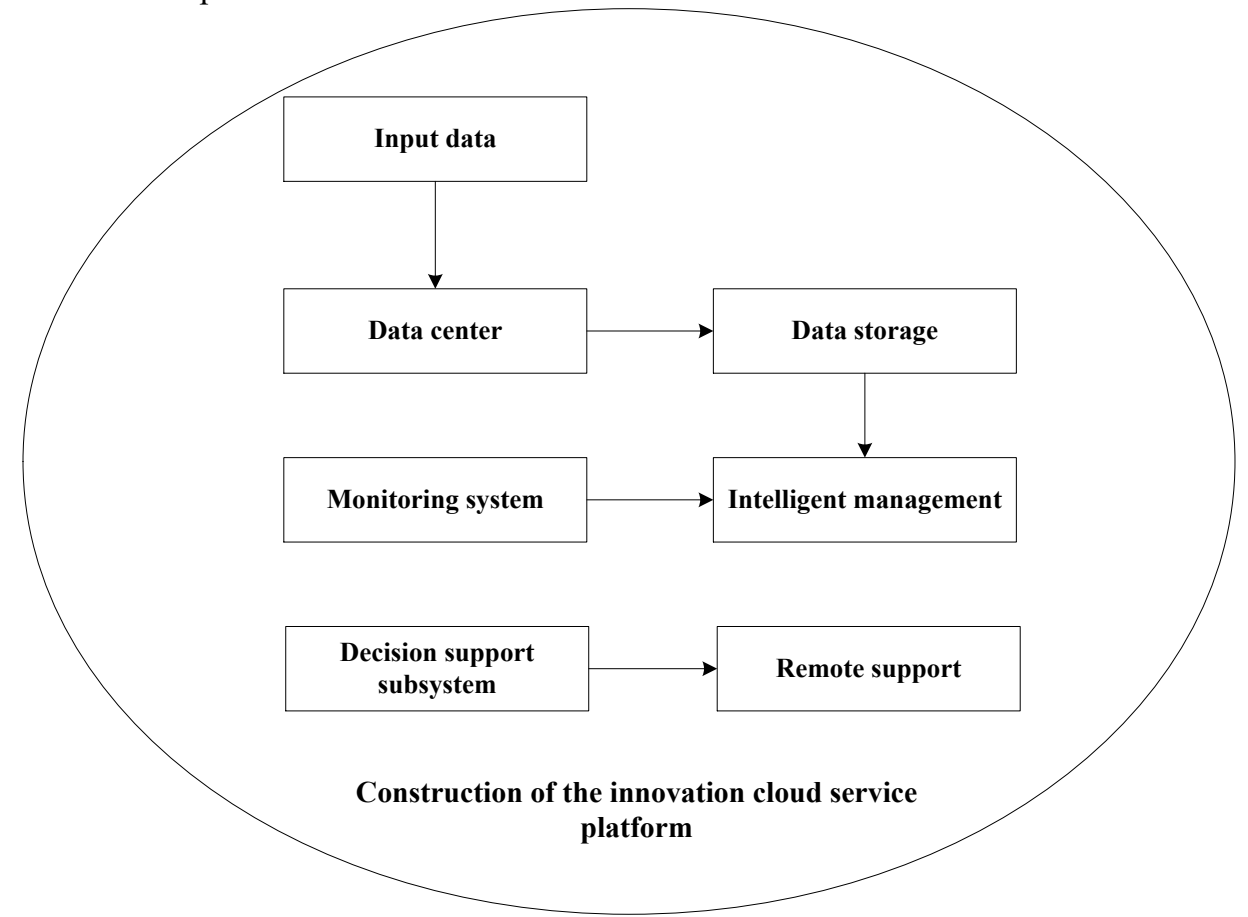

Fig. 1 The main functions and combinations of the innovation innovation cloud service platform. 


\section{Conclusion}

In this paper, the construction of the innovation innovation cloud service platform is studied. The main objectives of the innovation innovation cloud service platform can be mainly summarized as data sharing, intelligent management, and remote support. To achieve these objectives, the data center, monitoring system, and decision support system should be developed. The three systems work cooperatively to make the whole power system operate smoothly. With the progress in the artificial intelligence, more high-performance technologies could be applied to the construction of the innovation innovation cloud service platform.

\section{References}

1. Borlea I, Buta A and Dusa et al. 2005 DIASE-Expert system fault diagnosis for Timisoara $200 \mathrm{kV}$ Substation in Proc. EUROCON pp 221-224.

2. Wang Y and Pan Z 2011 Study on test technology of smart substation secondary system in Proc. International Conference on Consumer Electronics, Communications and Networks pp 1-4.

3. Kezunovic M 2009 Substation fault analysis requirement in Proc. IEEE Power \& Energy Society General Meeting pp 1-2.784-787

4. Lian J, Li H and Song K 2011 The analysis and corrective measures of common problems of $10 \mathrm{kV}$ capacitor bank in substation in Proc International Conference on Advanced Power System Automation and Protection pp 1750-1752

5. Gogan P L and Wyckoff G D 2012 Design and construction of sustainable substations in Proc. PES T\&D pp 1-4.

6. Li Q, Zhou Z and Du D, et al. 2013 A novel substation area backup protection for smart substation in Proc. IEEE PES Asia-Pacific Power and Energy Engineering Conference pp 1-4.

7. Wang Z, Jin $\mathrm{N}$ and Zhang J, et al. 2014 Fault information and diagnosis modelling of on-line communication monitoring system for digital substation in Proc. IEEE PES General Meeting | Conference \& Exposition pp 1-5.

8. Liu Y, Gao H and Gao W, et al. 2017 Development of a substation-area backup protective relay for smart substation IEEE Transactions on Smart Grid vol 8 no 6 pp 2544-2553.

9. Zhang H, Dou R and Zhi M, et al. 2016 The technology of interlocking logic visualization for smart substation in Proc. China International Conference on Electricity Distribution pp 1-4.

10. Li Z and Ma Q 2018 Discussion on optimization measures of relay protection technology in intelligent substation in Proc. IEEE Advanced Information Management, Communicates,
Electronic and Automation Control Conference pp 1593-1596.

11. Topolsky D V, ToPolskaya I G and Topolsky N D 2018 Development of an intelligent measuring system for digital substations in Proc. pp International Multi-Conference on Industrial Engineering and Modern Technologies 1-4.

12. Nassu B T, Lourival L and Bruno M et al. 2018 Image-based state recognition for disconnect switches in electric power distribution substations in Proc. SIBGRAPI Conference on Graphics, Patterns and Images pp 432-439.

13. Nichani A M and Swarup S 2018 Modelling and simulation of digital substation automation for intersubstation line protection in Proc. National Power Systems Conference pp 1-6.

14. Gao X and Wang Y 2013 Research of digital community service platform based on cloud computing in Proc. 8th International Conference on Computer Science \& Education pp 1-4.

15. Koo J, Kin Y and Lee S 2019 Security Requirements for Cloud-based C4I Security Architecture in Proc. International Conference on Platform Technology and Service (PlatCon) pp 1-4.

16. Cheng G 2010 Data center management plan in cloud computing environment in Proc. International Conference on Information Management, Innovation Management and Industrial Engineering pp 376-380.

17. Cheng G 2010 Data center management plan in cloud computing environment in Proc. International Conference on Information Management, Innovation Management and Industrial Engineering pp 393-396.

18. Qin X, Lin B and Ma S, et al. 2014 Study of the application of active power adjustment and control technology based on modem energy storage into power system stability control and voltage adjustment in Proc. International Conference on Power System Technology pp 1-4.

19. Song S, Bin T and Yang Q. 2005 Study on wide area measurement system based transient stability control for power system in Proc. International Power Engineering Conference pp 1-4.

20. Sun A, Zhou J and Ji T, et al. 2011 CSB: Cloud service bus based public SaaS platform for small and median enterprises in Proc. International Conference on Cloud and Service Computing pp 321-324.

21. Chung K and Keum C. 2014 Access control management of the innovation cloud service platform in Proc. International Conference on Information and Communication Technology Convergence pp 1-4. 